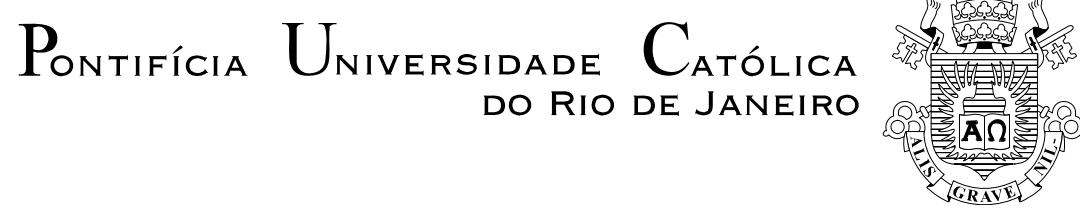

Helena Kale Pimentel Brazão

Orkut: do Escapismo ao Real Mediado, do Usuário ao Sujeito

Dissertação de Mestrado

Dissertação apresentada como requisito parcial para obtenção do grau de Mestre pelo Programa de Pósgraduação em Comunicação Social do Departamento de Comunicação da PUC-Rio.

Orientadora: Profa. Vera Lúcia Follain de Figueiredo 


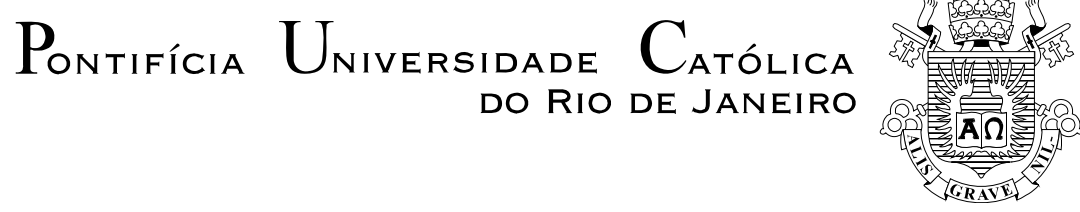

Helena Kale Pimentel Brazão

\section{Orkut: do Escapismo ao Real Mediado, do Usuário ao Sujeito}

Dissertação apresentada como requisito parcial para obtenção do grau de Mestre pelo Programa de PósGraduação em Comunicação Social do Departamento de Comunicação Social do Centro de Ciências Sociais da PUCRio. Aprovada pela Comissão Examinadora abaixo assinada.

Profa. Vera Lúcia Follain de Figueiredo Departamento de Comunicação Social - PUC-Rio

Orientadora

Profa. Ana Claudia Coutinho Viegas Departamento de Comunicação Social - PUC-Rio

Fernando do Nascimento Gonçalves UERJ

Prof. João Pontes Nogueira Vice-Decano de Pós-Graduação do CCS 
Todos os direitos reservados. É proibida a reprodução total ou parcial do trabalho sem autorização da universidade, da autora e da orientadora.

\section{Helena Kale Pimentel Brazão}

Gerente de Comunicação e Marketing do Santander (Segmento Universidades), jornalista e mestre em Comunicação Social pela PUC-Rio, com passagem pela área de projetos de Comunicação interna do Santander, pela Assessoria de Imprensa e pelo Marketing Corporativo da Souza Cruz.

Ficha Catalográfica

Brazão, Helena Kale Pimentel

Orkut: do escapismo ao real mediado, do usuário ao sujeito / Helena Kale Pimentel Brazão ; orientadora: Vera Follain de Figueiredo. - 2007

$133 \mathrm{f.} ; 30 \mathrm{~cm}$

Dissertação (Mestrado em Comunicação Social) Pontifícia Universidade Católica do Rio de Janeiro, Rio de Janeiro, 2007.

Inclui bibliografia

1. Comunicação social - Teses. 2. Identidade. 3. Comunidade. 4. Ciberespaço. 5. Orkut. I. Figueiredo, Vera Follain de. II. Pontifícia Universidade Católica do Rio de Janeiro. Departamento de Comunicação Social. III. Título.

CDD: 302.23 


\section{Agradecimentos}

Aos Professores do Departamento de Comunicação da PUC-Rio, à coordenação de pós-graduação, à secretaria de pós-graduação e, em especial, à Vera Follain de Figueiredo e à Marise Lira, pela paciência e atenção; para Elizabeth Brazão e Adrian Cané, pelo amor e apoio incondicionais. 


\section{Resumo}

Brazão, Helena Kale Pimentel Brazão; de Figueiredo, Vera Follain (Orientadora). Orkut: do Escapismo ao Real Mediado, do Usuário ao Sujeito. Rio de Janeiro, 2007. 133p. Dissertação de Mestrado Departamento de Comunicação Social, Pontifícia Universidade Católica do Rio de Janeiro.

Este trabalho terá como foco o Orkut, suas ferramentas identitárias e as apropriações idiossincráticas que cada sujeito realiza para se representar naquele espaço virtual. Parte-se do princípio de que, por sua organização, o Orkut é um lócus onde o sujeito pode tentar construir uma unidade, ainda que discursiva. Por se constituir como um espaço de imersão narrativa, o site de relacionamentos estabelece uma gramática própria, tornando-se suporte identitário. O indivíduo se apropria desta gramática e subverte suas regras. Desta forma, cria novas linguagens e recursos para potencializar a comunicação. No universo codificado de um site como o Orkut, os usuários se apoderam da tecnologia como meio de produção de subjetividade.

\section{Palavras-chave}

Identidade, comunidade, ciberespaço, Orkut. 


\section{Abstract}

Brazão, Helena Kale Pimentel Brazão; de Figueiredo, Vera Follain (Advisor). Orkut: from Escapism to Mediated Reality, from User to Individual. Rio de Janeiro, 2007. 133p. MSc. Dissertation Departamento de Comunicação Social, Pontifícia Universidade Católica do Rio de Janeiro.

This work will focus on Orkut, your identity tools and it idiosyncratic appropriations that each individual produce to represent themselves in that virtual space. Takes the premise that, by your organization, Orkut is the locus where individuals can try to build an unity, even in a discursive way. As a space constituted by immersion on narrative, this site establishes it own grammar, turning into identity support. Individuals take it self this grammar and subvert his rules. This creates new languages and potential resources to communication. In sites of coded universe as Orkut, users appropriate technology as a way to produce subjective.

\section{Keywords}

Identity, community, cyberspace, Orkut. 


\section{Sumário}

1. Introdução 9

2. O Orkut $\quad 15$

O que é Orkut 15

O Orkut pelo Orkut 18

As ferramentas para a construção de perfis e comunidades no Orkut 21

Regras do Orkut 26

Convergência de mídias $\quad 28$

$\begin{array}{ll}\text { Orkut: meio frio arrefecido pelo sujeito } & 29\end{array}$

A escrita no Orkut 31

3. Novas formas de produção de subjetividade 39

Orkut como diário íntimo $\quad 39$

Orkut, mídia e espetáculo do eu: a narrativa do sujeito 48

O valor da exterioridade $\quad 54$

Palco digital $\quad 62$

Mito de Narciso: o reflexo obtuso da imagem 66

$\begin{array}{ll}\text { Mais discurso do que ação } & 67\end{array}$

$\begin{array}{ll}\text { 4. Comunidade e identidade } & 74\end{array}$

Comunidades e suas diferentes visões de mundo $\quad 74$

5. Conclusão 112

Territorialização de identidades em tempo e espaço móveis 112

6. Referências bibliográficas 129 
"Sem necessitar de armas, violências físicas, coações materiais. Apenas um olhar. Um olhar que vigia e que cada um, sentindo-o pesar sobre si, acabará por interiorizar, a ponto de observar a si mesmo; sendo assim, cada um exercerá esta vigilância sobre e contra si mesmo."

(Michael Foucalt - Microfísica do Poder, p. 218) 